\title{
Demand for Responsible Leadership in a Chaotic World
}

\author{
Vladimir Yakunin
}

\begin{abstract}
There is a need to find new mechanisms that will allow nations and civilisations to cooperate better on specific issues despite their ideological differences. The current crisis is global and systemic in nature. On the one hand, this is an inevitable result of globalisation. On the other hand, it is a result of defects in the existing economic model and global political system. In the context of the global order and governance crisis, the roles and responsibilities of states are strengthening and a new type of global leadership is required. The emergence of a global threat, or catastrophe, should motivate states to put aside ideological differences and economic and political competition in search of a joint solution in the name of survival of human civilisation. The most recent threat has been the danger of new diseases in the form of global pandemics. To combat such threats effectively, we need to cooperate within the paradigm of "a community for the shared future of mankind" that combines the positive human potential of diverse civilisational identities, state structures, social and economic features, as well as cultural and historical diversity. By working together, we can bring order to the existing global disorder and find a way to secure the greater prosperity of humanity.
\end{abstract}

Keywords A need to find new mechanisms that will allow nations and civilisations to cooperate better - Global systemic crisis - Defects in the existing economic model and global political system $\cdot$ Roles and responsibilities of states are strengthening - A new type of global leadership is required - Search of a joint solution in the name of survival of human civilization - "A community for the shared future of mankind"

\section{A New Type of Global Leadership is Required}

Whenever humanity experiences challenges, those challenges are seen as unique. But this is only our perception. History in fact gives us many lessons of global crisis survival, whether it be future pandemics, cyber threats, poverty or the biggest threat

V. Yakunin ( $\square)$

Faculty of Political Sciences, Lomonosov Moscow State University, Moscow, Russia

(C) The Author(s) 2021

H. Wang and A. Michie (eds.), Consensus or Conflict?, China and Globalization, https://doi.org/10.1007/978-981-16-5391-9_9 
of all-climate change. We need to find new mechanisms that will allow nations and civilisations to cooperate better on specific issues, despite their ideological differences.

The current crisis is global and systemic in nature. On the one hand, this is an inevitable result of globalisation. On the other hand, it is a result of defects in the existing economic model and global political system. In the context of the global order and governance crisis, the roles and responsibilities of states are strengthening and a new type of global leadership is required.

The demand for a new model of leadership that provides global solidarity is growing sharply. Combating the current pandemic and similar global challenges should become the foundation for this sort of development. The question is what country or group of countries can initiate such a project and involve the rest of the world in its implementation, thereby demonstrating responsible leadership.

This is an ideal challenge and an excellent opportunity to take the initiative and make a bid for a new format of world development. If this model of responsible leadership in a multilateral world is successful, an evolutionary transition to new models of sustainable development will be quite possible.

In the last few years, more and more major powers have put their own national interests first. This raises the question of what kind of "leadership" the world actually needs. The problem with what we are seeing today is that we have so-called leaders who follow ideologies of exclusivity and superiority.

Adopting a zero-sum perspective is an over-simplified way of understanding international relations. A multilateral world should be based on equal cooperation, not necessarily in the military or even economic terms, but with equal opportunity and ability to engage in global dialogue. In the context of the crisis in global order and governance, state systems are faced with the need to form anti-crisis and post-crisis policies that can ensure public dialogue and consensual decision-making to reduce inequality and social tension. Political systems should be adjusted to ensure broader and more effective public representation in order to mitigate against irresponsible populists rising to power. It is possible that we may see new forms of political participation, as well as an expanded space for the digitalisation of public policy and management to address these issues. There is demand for an adequate level of international cooperation, particularly in economic and humanitarian spheres, in order to prevent the worsening of socio-economic crises. Ensuring this will require that relevant international institutions have maximum stability.

Over the past decades, the main drivers of globalisation and key participants in international processes have been the countries of the developed world-mainly representing the so-called Western world. The social, economic and political structure of these countries was a model for almost all other states. At the heart of the universal measurement of national well-being was the economic indicator of Gross Domestic Product (GDP), which endorsed the advantages of the chosen development models of Western countries compared to the rest of the world. As a result, the processes of globalisation have been based on technologies, values and a way of life inherent to Western societies. 


\section{The Emergence of a 'Financialised' World Economy}

It is no secret that the crisis of 2007-2008 began with the subprime mortgage collapse in the United States. This was due to low quality financial instruments-'derivatives' - that created a financial bubble such that the real value of goods was substantially overvalued due to a 'frenzied demand' based on incorrect information about economic realities. In practical terms, the world economy became 'financialised'; i.e., the financial sector of the economy increasingly dominated the real sector. This uncontrolled imbalance eventually led to the financial crisis and later to the global systemic crisis.

The financial crisis of 2008 led to a lower level of investment in infrastructure projects globally. On the one hand, governments reduced investment in long-term infrastructure because this was less painful than cutting other budgets at a time when it was essential to secure the provision of basic necessities. On the other hand, private investors also turned away from infrastructure projects and towards more liquid assets and projects with quick returns.

Numerous studies conducted after the crisis demonstrated a positive correlation between investment in infrastructure and economic growth. More importantly, it was also shown that infrastructure projects play a positive role in short-term outcomes as well, due to their creation of new jobs and their development of local enterprises, which support long-term regional development. Another conclusion voiced by many prominent economists over the last ten years has been the need to develop a new economic model to replace the existing neoliberal system, because neoliberalism no longer meets the needs of many states. Such statements were difficult to imagine before the crisis, but now seem obvious.

\section{Creating New Integrated Global Values}

This crisis shows that the world needs a new protocol for international relations and new responsible leadership if it is to be better prepared for future crises of this scale. So far, development has been based on values such as market capitalism, GDP growth and competition. We should be very careful when speaking about poverty and see this metric only in financial terms, as is the case today among key international organisations. We must follow human development through an integrated approach that takes into account access to healthcare, education and basic living standards. Going forward, I am convinced we need to be driven by values of solidarity, responsibility and a shared commitment to overcoming poverty and inequality. We must offer a new platform and paradigm for global powers to work together, including global North-South and South-South cooperation.

Taking into account the scale of the Belt and Road Initiative and the amount of investment China has put into it through newly founded multilateral financial institutions like the Asian Infrastructure Investment Bank, the New Development 
Bank and the Silk Road Fund, it is not surprising that major powers including the European Union and the US are expressing significant concerns.

On the one hand, this is due to an inherent Western scepticism about any initiative offered by the non-Western world. On the other hand, as the geography of the project expands and its support grows across the developing world, Western countries are beginning to worry that their long-dominant positions are becoming untenable. This is also a consequence of the fact that, for a long time, traditional international development institutions did not provide the necessary weight for developing countries to participate in the global financial system, given their real contribution to global economic development alongside their institutional voting power and roles.

At the same time, the core concept of the Belt and Road initiative- 'equal and mutually beneficial cooperation without imposing any political conditions'-clearly contradicts the currently dominant thesis in contemporary world politics. This new approach could change the very essence of geopolitics and geoeconomics by altering the outdated Cold War mentality of the past. Geopolitical theory has always been articulated through a lens of conflict, dividing the world into 'us' and 'them'. The pervading instability of ongoing trade wars and sanctions contribute their own limitations, which will need to be overcome and are mainly derived from economic relations between the US and other countries, primarily China. The Belt and Road Initiative could be the source of a future model of solidarity-driven global development.

Today, with the countries of Asia and Africa developing rapidly, we are observing the emergence of new leaders on the global stage, and a corresponding decrease in Western representation. As a result, we can conclude that the international architecture is currently undergoing a transition from a dominant Western-centric model to a new model that should take into account the needs of the developing world and its cultural diversity. An essential factor in determining the effectiveness of international relations in the modern multilateral world is deep knowledge about the different cultures, mentalities and values that underpin the formation of state policies in different countries. It is incorrect to view the developing world through the standards of the Western world.

\section{Creating Solidarity-Driven Development}

The key here is the impossibility of returning to a unipolar or bipolar world, which can be seen today in global trends towards development of a truly multilateral world. The change towards solidarity-driven development, which we see in the Belt and Road Initiative, provides a very different perspective. This enables consideration of external geopolitical and geoeconomic zones not as sources of danger, but as parts of a planet-wide life-support mechanism for development at local, regional and global levels.

Critical issues for the development of global initiatives include deficits of leadership, practical skills and knowledge to manage and support dialogue-based international cooperation towards human-centric development goals. Experts within and 
beyond the policymaking community should foster serious scholarly and practical efforts to support the research and development of new socio-economic models, based around solidarity-driven development, in which cooperative multilateral mechanisms are used. The question is which country or group of countries can put forward such a project and involve the rest of the world in its implementation, demonstrating 'value leadership'. This is a good challenge and an opportunity to take the initiative and make a bid for a new format of world development. If such a model of 'cooperative leadership' is successful, an evolutionary transition to new models of economic development will be quite possible.

Since the start of the pandemic and the ensuing crisis, politicians, government officials and experts across the globe have become increasingly aware of the magnitude and systemic nature of the problems at hand. This has created grounds for cautious optimism. That said, much remains to be done, and it will require collaboration between the state, the private sector and the public, as well as cooperation between governments at different levels and across different platforms.

Any form of dialogue-bilateral, trilateral, multilateral-is better for inclusive international development and peace than geopolitical competition. From this perspective, trilateral dialogue between the US, China and Russia is a necessary condition for future prosperous development. If we are talking about the possibility of trilateral dialogue, we need to answer three questions:

(1) Do the parties have the motivation to engage in joint dialogue?

(2) Is there a risk that dialogue among these three states could develop into a situation in which two participants compete or "team up" against the third one?

(3) Will cooperation among the three become a conspiracy of the three against the rest of the world?

Today we have more grounds for drawing negative conclusions in response to these issues. This is undoubtedly a matter of serious concern. We need to concentrate our intellectual efforts on researching and defining the theoretical foundations for overcoming this tension, and provide practical recommendations on how to reestablish international cooperation based on the values of dialogue, inclusion and solidary development.

A key trend in global affairs is that developing countries are accounting for a greater share of global economic output. This clearly illustrates that when speaking about international development we must take into account new centres of political and economic growth and interactions among these centres. In this time of crisis, only solidarity among nations can help us to weather the storm. It is time to address critical global issues together. We should not let historical baggage and cultural biases prevent us from moving forward. We need to offer a new system and principles and build a new type of international leadership that will take into account the interests of the emerging world in Asia, Latin America and Africa, and help to avoid future global threats. 


\section{The Demand for New Leadership}

Modern international leadership requires a number of qualities that are currently missing:

- The ability to see the global picture;

- The ability to see pathways to long-term sustainable global development, without being limited by considerations of electoral cycles or short-term political gain;

- The ability to unite people in the face of global threats.

The demand for new leadership is being met through specific actions and initiatives. A good example of maintaining such policies is China, whose government provides active assistance to countries across all continents by using China's manufacturing and technological capacities. The launch of projects such as the Health Silk Road and the Digital Silk Road is a great example of a country responding to the ongoing crisis appropriately and in a flexible manner. We can also observe the pragmatic policies of several European countries, which in times of bureaucratic uncertainty, are making independent decisions related to the need for economic development or the provision of medical goods.

We should remember that every crisis is also an opportunity. Humanity is now aware that it is facing new global challenges - such as climate change, for example. By properly reacting to these new challenges, we have a chance to undergo technological modernisation - and emerge from the crisis as a renewed society, more sustainable than before. But the only way for these changes to be successful is to first ensure social and economic sustainability - to make sure that interests of businesses and communities are not ignored at a national level, and that the interests of individual countries are respected on a global level. Securing this type of balanced development is a goal that all of us share.

Geopolitics is a kind of geographically construed politics, an intermediate science that focuses on political events and endeavours to provide them with a geographical interpretation within state borders. In contrast, the geographical boundaries of civilisations determine the natural boundaries of influence of great powers and remove any limitation and artificiality from geopolitics, supplementing it with essential and substantial value.

By defining China and Russia as independent civilisations, and the United States as the leader of Western civilisation, we can determine actual boundaries and spaces of interaction. We can easily observe that interaction in these spaces is far from positive. Most regions are filled with political and economic instability, and many of them are engulfed in military conflict. One of the most dangerous factors of this confrontation is that the religious and cultural foundations of local societies are becoming radicalised, which leads to a degradation and possibly the loss of traditional ways of life, and dependence on external resources.

The idea of a geopolitical division of the world between a limited group of stateswhether two, three, five or some other number-is not new from a historical perspective. One look at the twentieth century and we can see the dangerous consequences of 
this, when a country or group of countries choose a strategy of exclusivity over others. During the Cold War, geopolitical games included not only containment strategies, but also the purposeful strengthening of other states or local groups to confront geopolitical opponents. Today, we see new mechanisms of influence outside the norms of international law. One example of such external influence is sanctions, which have become part and parcel of achieving economic and political goals in different countries. The possibility of using such instruments, as well as a tacit lack of action to give developing countries a corresponding role or vote weight in international institutions, are clear signals of the need to reform existing institutions of international cooperation such as the International Monetary Fund (IMF), World Bank and its related bodies.

\section{The Impact of the Digital Revolution}

Modern civilisational analysis cannot be complete without evaluating a new factor - the development of information technologies and social networks-which is becoming a comprehensive element of geopolitics itself. Russia, China and the US represent major players in this field among global powers.

I would like to touch upon a new phenomenon that we have termed 'the madness of the digital crowd'. Sociology provides a lot of information on the effect of irrationality and destructive behaviour caused by the influence of crowd forces. We realise from geopolitics that hidden manipulative crowd control is one of the most common techniques of indirect external influence. In addition to this, algorithms create an echo-chamber effect, which leads to polarisation of views and reduces opportunities for forming a comprehensive and fact-based understanding of events. Combined with modern informational systems and algorithms, we can see a new level of control and manipulation of the daily news agenda at both the individual and global levels. Under these conditions, any person or organisation can be rendered defenceless in the face of an attack by a 'digital crowd', which could be transitioned into the real world on the same scale. At the same time, there is a new phenomenon called 'deplatforming', whereby a person or organisation is denied the opportunity to express their opinion by private actors. This threat should also be the subject of research as part of the development of new foundations for international cooperation towards peace and inclusive development.

\section{Towards a Dialogue of Civilisations}

The emergence of some kind of global threat or catastrophe should motivate states to put aside ideological differences and economic and political competition in search of a joint solution in the name of survival of human civilisation. Such a threat can be 
seen in the danger of new diseases in the form of global pandemics as with COVID19. To combat these threats effectively we need to cooperate within the paradigm of "a community for the shared future of mankind". In this situation, we will be able to rely on the common value of human life for all, while preserving life for future generations.

The concept of a dialogue of civilisations is in fact a way of building a global community. It combines the positive human potential of civilisational identities, state structures, social and economic features, as well as cultural and historical diversity. By working together, we can bring order to the existing global disorder and find a way to secure greater prosperity for humanity.

Vladimir Yakunin is a Russian public figure and academic. Currently, he serves as the Head of the State Policy Department at Lomonosov Moscow State University and as a Visiting Professor at Peking University. He occupied various positions in business and public service, including in the Presidential Administration of the Russian Federation and was Deputy Minister of Transport. In 2005-2015, Dr. Yakunin served as President of Russian Railways. In 2003, Dr. Yakunin co-founded the World Public Forum-Dialogue of Civilizations, which brings together diverse perspectives from the developed and developing states in a non-confrontational, equal, inclusive and collaborative way. In Russia, he also leads a number of public, philanthropic, social and educational initiatives.

Open Access This chapter is licensed under the terms of the Creative Commons AttributionNonCommercial-NoDerivatives 4.0 International License (http://creativecommons.org/licenses/bync-nd/4.0/), which permits any noncommercial use, sharing, distribution and reproduction in any medium or format, as long as you give appropriate credit to the original author(s) and the source, provide a link to the Creative Commons license and indicate if you modified the licensed material. You do not have permission under this license to share adapted material derived from this chapter or parts of it.

The images or other third party material in this chapter are included in the chapter's Creative Commons license, unless indicated otherwise in a credit line to the material. If material is not included in the chapter's Creative Commons license and your intended use is not permitted by statutory regulation or exceeds the permitted use, you will need to obtain permission directly from the copyright holder.

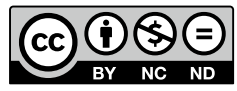

